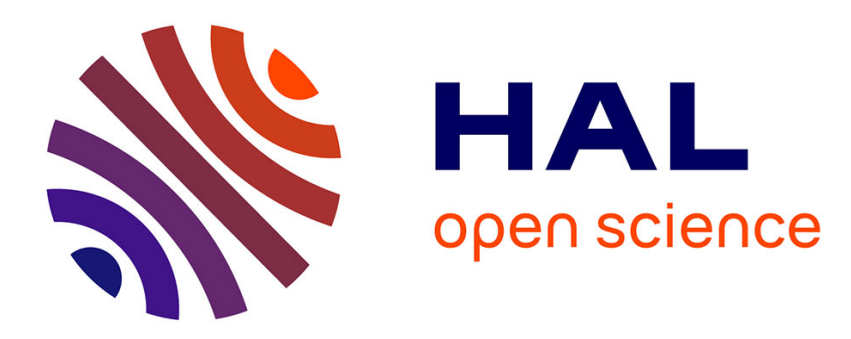

\title{
Biotic and abiotic drivers of species loss rate in isolated lakes
}

\author{
Céline Bellard, Göran Englund, Bernard Hugueny
}

\section{To cite this version:}

Céline Bellard, Göran Englund, Bernard Hugueny. Biotic and abiotic drivers of species loss rate in isolated lakes. Journal of Animal Ecology, 2019, 88 (6), pp.881-891. 10.1111/1365-2656.12980 . hal-02285059

\section{HAL Id: hal-02285059 \\ https://hal.sorbonne-universite.fr/hal-02285059}

Submitted on 12 Sep 2019

HAL is a multi-disciplinary open access archive for the deposit and dissemination of scientific research documents, whether they are published or not. The documents may come from teaching and research institutions in France or abroad, or from public or private research centers.
L'archive ouverte pluridisciplinaire HAL, est destinée au dépôt et à la diffusion de documents scientifiques de niveau recherche, publiés ou non, émanant des établissements d'enseignement et de recherche français ou étrangers, des laboratoires publics ou privés. 
Title:

2 Biotic and abiotic drivers of species loss rate in isolated lakes

3

4 Short title: Age effects on extinction rates

$5 \quad$ Extinction rates in lakes

6

7

$8 \quad$ C. Bellard ${ }^{1}$, G. Englund ${ }^{2} \&$ B. Hugueny ${ }^{3}$

$9 \quad{ }^{1}$ Unité Biologie des organismes et écosystèmes aquatiques (BOREA UMR 7208) Muséum

10

11

12

13

14

15 national d'Histoire naturelle, Sorbonne Universités, Université Pierre et Marie Curie, Université de Caen Normandie, Université des Antilles, CNRS, IRD; 43 rue Cuvier, CP26, 75005, Paris, France

${ }^{\mathbf{2}}$ Department of Ecology and Environmental Science, Umeå University, 90187 Umeå, Sweden

${ }^{3}$ Laboratoire Évolution \& Diversité Biologique (EDB UMR 5174), Université de Toulouse Midi-Pyrénées, CNRS, IRD, UPS. 118 route de Narbonne, Bat 4R1, 31062 Toulouse cedex 9, France.

Keywords: aquatic ecosystems, isolation, piscivores, age, fragmentation, 
23

\section{Summary}

1. Today, anthropogenic impacts are causing a serious crisis for global biodiversity, with rates of extinction increasing at an unprecedented rate. Extinctions typically occur after a certain delay and understanding the mechanisms causing delays is a key challenge for both fundamental and applied perspectives.

2. Here, we make use of natural experiments, the isolation of lakes by land up-lift in Northern Scandinavia, to examine how yearly extinction rates are affected by time since isolation and a range of abiotic and biotic factors.

3. In this aim, we adapted a model of delayed species loss within isolated communities to test the effects of time since isolation, area, $\mathrm{pH}$, depth and presence/absence of piscivores on extinction rates.

4. As expected, we found that small and/or young lakes experience a higher annual rate of extinctions per species than larger and/or older ones. Compared to previous studies that were conducted for either young (few thousand years ago) or very old (>10 000 years ago) isolates, we demonstrated over a large and continuous temporal scales (50-5000 yr), similar relationship between extinction rates and age. We also show that extinction rates are modified by local environmental factors such as a strong negative effect of increasing $\mathrm{pH}$.

5. Our results urge for the need to consider the time since critical environmental changes occurred when studying extinction rates. In a wider perspective our study demonstrates the need to consider extinction debts when modeling future effects of climate change, land-use changes, or biological invasions on biodiversity. 


\section{Introduction}

Today, we are facing the sixth wave of extinctions of our planet (Ceballos et al., 2017; De Vos et al., 2014). In most of deep time, extinctions occurred at a fairly constant rate, called background extinction rate. Today, human activities have raised extinction rates several orders of magnitude above this level. For example, the current rate of extinctions for vertebrates is more than 100 times the background rate, with literally ca. 4 vertebrates going extinct every year since 1900 (Ceballos et al., 2015). Land use changes are responsible for most of the modern extinctions (Collen et al., 2014; Leclerc et al., 2018; Pereira et al., 2010; Sala et al., 2000). Habitat destruction and altered land use have reduced previous continuous habitats to isolated fragments. Local and regional species extinctions may follow but not immediately, leading to decreasing species richness over time at several spatial scales. This means that the ecological cost of current habitat fragmentations could be delayed, a phenomenon termed extinction debt. Studies of extinction debts in a wide range of taxa and ecosystems (Harding et al., 1998; Piessens and Hermy, 2006; Piha et al., 2007) has shown that the time until extinctions take place may vary from weeks and months to hundreds or thousands years (Shaw et al., 2013; Uezu and Metzger, 2016). This gradual loss of species (also known as faunal relaxation to refer, in physics, to the return of perturbed system into equilibriumhas first studied by Diamond (1972) and have since been studied in many different systems (Cousins and Vanhoenacker, 2011; Hugueny et al., 2011; Hylander and Ehrlén, 2013; Kuussaari et al., 2009). This observation is particularly important for conservation, as the time from impact to extinction provides a time window within which remedial actions can be taken. Moreover, understanding mechanisms of delayed extinction is essential for predicting the impact of global changes on biodiversity. A range of intrinsic and extrinsic mechanisms may influence the timing and sequence of species losses, including the increased risk of stochastic extinction faced by small populations size and species have narrow habitat 
requirement (e.g., Almeida et al. 2017). At the regional scale, habitat modifications may result in disequilibrium meta-population dynamics (i.e., extinction and colonization rates are no more balanced), which also can lead to delayed extinctions (Helm et al., 2005). Species loss rates may be accelerated by inter-specific competition, predation, and anthropogenic impacts such as overexploitation and species invasions. Life history traits could also influence species' responses to extinctions (Krauss et al., 2010), e.g., long lived species are expected to persist longer than short lived species (Cronk, 2016; Lindborg and Eriksson, 2004).

Recent studies emphasize that species loss rates in isolated habitat fragments can be accurately modelled with a few predictors, like age and area of the isolate, for a large array of terrestrial taxa and for different types of fragments (e.g. true islands, forest remnants, mountaintops) (Halley et al., 2016; Hugueny, 2017). The negative relationship between species loss rate and area is well documented in the literature (Ferraz et al., 2003; Halley and Iwasa, 2011; He and Hubbell, 2011; Hugueny, 2017). Some of these studies also demonstrate that species decay curves often differ from the exponential decay expected for equivalent and non-interacting species. Instead of the constant species loss rate per unit time expected under an exponential decay, empirical data show that species loss rates decrease with increasing age of the isolate. This age effect could arise because the loss of species leads to reduced risk of extinctions due to species interactions, i.e., diversity-dependent dynamics (e.g., Halley et al. 2016). Alternatively, it can be the result of interspecific variability in extinction proneness. As species with high probability of extinctions disappear soon after isolation, the remaining community will consist of species with comparably low extinction risk (Ferraz et al., 2003; Hugueny, 2017).

Most studies of delayed extinctions have focused on terrestrial assemblages, and little is known about natural extinction rates of aquatic organisms in the absence of catastrophic events. Fortunately, freshwater fish populations frequently occur in isolated habitats such as 
lakes (Englund et al., 2009) and coastal rivers (Hugueny et al., 2011) that receive no or few colonists. Recently, Hugueny (2017) built a new theoretical model to test the effect of age and area on species loss rates in isolated terrestrial vertebrate communities. We believe the modeling framework built by Hugueny (2017) should prove useful in explaining species extinctions in aquatic systems and allow us to test for the contribution of aquatic variables to explain species loss rates. For instance, small and/or young (recently isolated) lakes and rivers should experience a higher annual rate of extinctions per species than larger and/or older ones. A former study of fish communities in coastal rivers isolated since the beginning of the Holocene confirmed the important contribution of the area of the isolate to extinction rates, but as the rivers became isolated at approximatively the same time the effect of age could not be studied (Hugueny et al., 2011). In fact, few fragmented systems in both terrestrial and aquatic environments allow studying species losses over long and continuous temporal scales. For instance, the fragments analyzed in recent meta-analyses are either young (a few hundred years for the older) and the result of human driven fragmentation, or very old (about 10,000 years) resulting from environmental changes that occurred at the end of the Pleistocene, with no values in between (Dias et al., 2017; Halley et al., 2016; Hugueny et al., 2011).

Here, we will study extinction rates of freshwater fishes in a natural experiment - bays transformed into lakes by land uplift caused by post-glacial isostatic rebound in Northern Sweden. Because the uplift rate was approximately constant over the last 4000 years, we can estimate the age of isolated lakes. This process has created lakes of various ages covering 0 to 5,000 years that provides an opportunity to study the time from isolation to extinction. Besides factors acting across taxon and types of fragment, we expect that specific mechanisms of lacustrine ecosystems are also important in shaping species decay through time. For instance, acidification is known to cause extinctions of fish species (Holmgren, 2014), and depth is known to mediate the effects of piscivorous fishes on their prey in this 
system (Englund et al., 2009). Indeed, shallow lakes are known to serve as a refuge for prey species, while deep lakes are particularly favorable to the presence of two dominant piscivores, Eurasian perch and northern pike. Yet, the relative importance of area, age, depth, $\mathrm{pH}$, and piscivory for extinction patterns have not been unexplored in aquatic ecosystems (justification of used variables are provided in the material and method section). In this study, we adapt the modelling approach introduced by Hugueny (2017) to examine the effects of these factors on extinction rates.

\section{Material and Methods}

\section{Study sites:}

Lakes are classified as either (i) connected if they are linked to the Baltic Sea by a permanent stream with a gentle gradient or (ii) isolated if they lack permanent stream connections or if their outlet streams have steep sections that act as a dispersal barrier (see Englund et al., 2009). The isolated lakes are not connected to upstream lakes with fish. Thus, all the isolated lakes are fully disconnected from other sources and no event of colonization has been recorded. The study sites also included closed bays that were in the process of forming a lake, but were still well connected to the Baltic Sea with the water surface being in level with the surface of the Baltic Sea. The land uplift caused by the post-ice-age isostatic recovery is thus transforming bays in the Baltic sea to lake environments. Because of the low salinity of the Baltic Sea, it is inhabited by numerous freshwater fish species that could successfully invade bays and maintain self-sustaining populations in newly isolated lakes.

The dataset includes 71 isolated lakes, 41 connected lakes, and 12 closed bays located along the coast of the northern Baltic Sea, between latitudes and longitudes of $61.78^{\circ}-64.48^{\circ}$ and $17.30^{\circ}-21.42^{\circ}$ 
144 Detailed physical and chemical properties for a subset of the analyzed lakes are provided in 145 Öhman et al. (2006). In summary, these lakes are small, shallow, and oligotrophic. Primary 146 productivity in the area is limited by light rather than nutrients (Seekell et al., 2015). The 147 abiotic factors identified by previous studies as being important for fish species composition 148 include lake age, lake area, isolation from the Baltic Sea, $\mathrm{pH}$ and oxygen (Öhman et al., 2006, 149 Englund et al 2009). We do not have data on oxygen levels for most of the lakes, but previous 150 studies have shown that shallow depth is a good predictor of low oxygen levels (Englund et al., 2009; Öhman et al., 2006). Anthropogenic activities that may also affect species composition include treatment with the piscicide rotenone, liming, and species introductions. Thus, when selecting lakes, we interviewed fishery rights owners and excluded lakes where the interviewees claimed that such activities had occurred. Human activities in the catchments are minor and mostly concerns forestry and ditching for forestry production. The effects on fish extinction rates of these activities are largely unknown.

157 Consequently, we focus our analysis on the following environmental variables for bays, isolated lakes, and connected lakes were extracted from Englund et al. (2009). Digital maps were used to estimate each lake's area, catchment area, and distance to the sea while other variables were measured directly in the field. Elevations were estimated using either a highresolution GPS instrument or an automatic level. The maximum depth was measured from a boat with an echo-sounder and $\mathrm{pH}$ was measured with a portable $\mathrm{pH}$-meter.

For isolated lakes at low elevations $(0-30 \mathrm{~m})$ the time since isolation could be approximated by a linear equation, age $=100 *$ elevation $($ Renberg $\&$ Segerstrom 1981$)$ as the uplift rate was approximately constant the last 4,000 years (Berglund et al., 2004). The age of isolated lakes at higher elevations (>30m) was predicted with a log-log model based on data in Påsse et al., 
$(1996)(\log ($ Age $)=0.57 * \log ($ elevation $)+6.048$; see Appendix S1 for further details, with $\log$ as natural logarithms).

\section{Species richness}

Data on fish species richness (Sr) were extracted from Englund et al. (2009). Each lake was sampled summer time (June-Aug) on two different occasions during the period 1999-2007, with the aim to detect all fish species present. The methods used in each lake included minnow traps (5-10), spinning rods (90 min), and 2-4 multi-mesh gill nets. The sampling effort for gill nets and minnow traps was adapted to lake size following (Appelberg et al., 1995). The nets each had twelve 2.5 m sections, with knot-to-knot mesh sizes of 5, 6.25, 8 , $10,12.5,15.5,19.5,24,29,35,43$, and $55 \mathrm{~mm}$. To ensure detection of stickleback species, which were sometimes missed by the other methods, we also surveyed the littoral zone of each lake using either electricity (45 min) or small detonations ( $\mathrm{n}=10$ per lake; (Öhman et al., 2006). The salinity of the northern Baltic sea is low (0.1-0.4\%) so most (>90\%) of the fish species living in lakes are also present in the sea. Among isolated lakes, 18 lakes were fishless and for the other lakes species richness ranges from 1 to 4 . Species occurring in these lakes are nine-spined stickleback (Pungitius pungitius L.), three-spined stickleback (Gasterosteus aculeatus L.), roach (Rutilus rutilus L.), crucian carp (Carassius carassius L.), and two piscivores: perch (Perca fluviatilis L.) and pike (Esox Lucius L.). In bays and connected lakes we infrequently encountered eight additional freshwater species: bleak (Alburnus alburnus L.), bream (Abramis brama L.), ide (Leuciscus idus L.), ruffe (Gymnocephalus cernuus L.), rudd (Scardinius erythrophthalmus L.), dace (Leuciscus leuciscus L.), white bream (Blicca bjoerkna L.) and European minnow (Phoxinus phoxinus L.), and two marine species (herring: Clupea harengus and sprat: Sprattus sprattus). The dataset of the isolated lakes used for this study is available from the Dryad Digital Repository (Bellard et al., 2019). 


\section{Theoretical models to explore drivers of extinction rates}

Because no colonization events have been recorded in our isolated lakes and speciation are unlikely to occur in such short time scales, we assumed that the isolation has caused species richness to decrease over time. Under these conditions, the observed species loss rate equals species extinction rate. To model species loss rate, we adapted the modelling approach described in Hugueny (2017, Appendix S2, eq. S9) to deal with more explanatory variables. Using this approach, we modeled the effects of time since isolation $(t)$, lake area $(A), \mathrm{pH}(P)$, depth $(D)$, and presence/absence of piscivores (pisc) on the proportion of extant species at $t$ years after isolation:

$\mathrm{Sr}_{t} / \operatorname{Sr}_{0}=1 /\left[1+\left(c+v b^{*} \text { pisc }\right)^{*} m^{*}\left(A^{b}\right)^{*}\left(P^{x}\right)^{*}\left(D^{y}\right)^{*} t\right]^{1 / m}$

It is expected that, all else being equal, $\mathrm{Sr}_{\mathrm{t}} / \mathrm{Sr}_{0}$ decreases with age (as extinction events accumulate). The parameter $m$, in conjunction with the variable $t$, sets the shape of this species decay curve. Eqn (1) is undefined when $m=0$, but as $m \rightarrow 0$, the dynamics approaches an exponential decay (constant species loss rate per species per year through time) with $\ln \left(\mathrm{Sr}_{t} / \mathrm{Sr}_{0}\right)$ being a linear function of $t$. Setting $m>>0$ results in a convex decreasing relationship between $\ln \left(\mathrm{Sr}_{t} / \mathrm{Sr}_{0}\right)$ and $t$, meaning that species loss rate per species per year is no more constant but slows down as time since isolation elapses (hereafter "Age effect").

The other parameters set the contribution of the selected variables to species loss, and can be interpreted as coefficients in a multiple regression. For instance, if $x$ is negative it means that, all else being equal, there is a negative relationship between $\mathrm{pH}$ and species loss rate. Because $\mathrm{pH}$ varies with age, we did not model the direct effect of $\mathrm{pH}$. Instead, we included as predictor the residuals of the model $(\log (\mathrm{pH}) \sim \log (\mathrm{Age}))$ to account for the $\mathrm{pH}$ variation that is not related to age. 
Note that the parameter $v b$, which describes the effect of piscivory, enters the equation differently to account for the binary nature of this variable (0: piscivores absent; 1 : piscivores present). Note also that the parameter $b$ has been constrained to be null or negative to be consistent with theoretical expectations. From eqn (1) different models could be fitted to the data by setting some parameters to zero (Table 1).

\section{Estimating species richness at the time of isolation}

Because of the constant rise of the land, the coastal bays are becoming isolated lakes with time. Moreover, as salinity in the bays are low $(<0.3 \%)$, all the species occurring in coastal lakes are also present in bays. Thus, we can expect that before isolation, species richness within isolated lakes were similar to either bays or connected lakes near the coastline. A common method to estimate species richness before isolation is to use the information about species richness from reference regions within a continuous piece of habitat but otherwise similar to the isolate of interest. Hence, we made the assumption that initial species richness for isolated lakes was similar to the species richness observed in connected lakes and bays and estimated $\mathrm{Sr}_{0}$ for isolated lakes based on stepwise regression models obtained. Based on connected lakes and bays dataset, we found that only area and elevation significantly influenced species richness when piscivores are included, while elevation and $\mathrm{pH}$ were the only significant predictors when piscivores were excluded (see Appendix 2 for details). Based on these minimum adequate models (Appendix $\mathrm{S} 2$ for details), we predicted $\mathrm{Sr}_{0}$ of isolated lakes, by setting elevation and distance to the sea equal to 0 and using modelled $\mathrm{pH}$-values and area. Thus, $\mathrm{Sr}_{0}$ was also calculated (i) when including all species that occurred in the connected lakes and bays, and (ii) when excluding the two piscivores, pike and perch. This resulted in two different estimates of $\mathrm{Sr}_{0}$ for each lake. Piscivores were excluded from $\mathrm{Sr}_{0}$ to allow assessment of their impact on the extinction rate of potential prey species. In all cases, 
if $\mathrm{Sr}_{\mathrm{t}}>\mathrm{Sr}_{0}$ we assumed that $\mathrm{Sr}_{\mathrm{t}}=\mathrm{Sr}_{0}$ and no extinction occurred. Table 2 presents the best models and their AICc values, and Appendix S4 and S5 show the parameters values.

\section{Estimations of parameter values and comparison between models}

For the sake of graphical comparison of observed and predicted values, we computed an average annual extinction rate per species per year over the period 0 -t as follows:

$k=-\ln \left(\operatorname{Sr}_{t} / \operatorname{Sr}_{0}\right) / t$

Observed and predicted $k$ are computed using the observed and predicted $\mathrm{Sr}_{\mathrm{t}}$, respectively, with the constraint $0<\mathrm{Sr}_{\mathrm{t}} / \mathrm{Sr}_{0}<1$ in the case of observed values.

Parameter values of eqn (1) were estimated by maximizing the likelihood of observing $\mathrm{Sr}_{\mathrm{t}}$ using the function 'nlminb' in the R environment (version 3.4.3, R Core Team, 2017). A binomial distribution for $\mathrm{Sr}_{\mathrm{t}}$ was assumed, using the integer part of $\mathrm{Sr}_{0}$ to set the number of trials and the right side of eqn (1) to compute the probability of success. In this way, and in contrast with Hugueny (2017), communities with 0 and $100 \%$ of extinct species can be considered. Then, we compared all the models using the Akaike information criterion (AICc) with AIC $=2 k-2 \log (L)$ with $k$ the number of estimated parameters and $L$ the log likelihood and $\mathrm{AICc}$ criteria as follows $\mathrm{AICc}=\mathrm{AIC}+\left(2 k^{2}+2 k\right) /(\mathrm{n}-k-1)$ with $n$ the sample number, defined for small samples (n/k <40) (Burnham, K. P. \& Anderson, 2002). The sensitivity of parameter estimates to initial species richness estimations (i.e., $\left.\mathrm{Sr}_{0}\right)$ were examined. In this aim, we modified $\mathrm{Sr}_{0}$ values by $10 \%$ (in other words, we first increase and then decrease $\mathrm{Sr}_{0}$ by $10 \%$ ) and assess how parameter values from equation (1) vary, compared to results from Table 2 and Appendix 4 and 5. 


\section{Results}

263

264

\section{Extinction rates at community level}

The average of the initial species richness $\left(\mathrm{Sr}_{0}\right)$ was 4.05 when including piscivore species, and 2.57 when excluding the piscivores. The observed extinction rate ( $k$ in eq. 3 ) ranged from 0.0001 to 0.008 (mean 0.0015 ) when including piscivores, and from 0 to 0.006 (mean 0.0013 ) when the piscivores were excluded (Appendix S6). From Figure 1, it is clear that observed extinction rates decrease with the time elapsed since isolation. If extinction rates are constant among species and through time, a flat relationship with age would have been expected. The relationship with area is negative, as expected, but relatively weak. We also observed a clear negative relationship between species loss rates and $\mathrm{pH}$ residuals (from a regression of $\mathrm{pH}$ on age).

Eq. 1 was used to examine the relationships between extinction rate in isolated lakes and the following variables: area, age, piscivores, $\mathrm{pH}$, and depth. In all models the parameter $m$, related with age, is positive and high, indicating that species loss rate departs strongly from an exponential decay, as shown by figure 1 . For both $\mathrm{Sr}_{0}$ estimates (with and without piscivores), the best model is the ApH model, which includes negative effects of area and $\mathrm{pH}$ on extinction rates (see Table 2 and Appendix S4 and S5 for parameter values). This model slightly outperforms the full model ( $\triangle \mathrm{AICc} 1-3.3)$ and is much better than all other models. The full model shows that extinction rate decreases with increasing area, $\mathrm{pH}$ and depth when piscivores are included. We also found a positive effect of piscivores on extinction rates (when they are excluded of the calculation of $\mathrm{Sr}_{0}$ ), meaning that extinction rate increases with the presence of piscivores (i.e., perch and pike), as well as depth. Overall, the ApH model provides a good fit to observed data (Figure 2). Note that models have been fitted with all the lakes, while only lakes having $0<\mathrm{Sr}_{t}<\mathrm{Sr}_{0}$ are plotted in figure 2 . The apparent overestimation of observed extinction rates occurs because fishless lakes (with high extinction rates) are not 
shown. Sensitivity analyses show parameter estimates are robust to variation in initial species richness, $\mathrm{Sr}_{0}$ (Appendix S6).

\section{Discussion}

Extinctions are rarely observable, particularly when they occur over centuries and millennia.

Habitats that became isolated many years ago, such as land-bridge islands created by sea level rise at the end of the Pleistocene, are valuable natural experiments to study extinction at work in natural communities. Such natural experiments, also known as relaxation, have greatly contributed to the estimation of extinction rates in terrestrial communities and to the identification of underlying ecological mechanisms. In contrast, freshwater ecosystems have been largely ignored in this regard and to our knowledge our study is the first to estimate and study species loss rate in isolated lakes following a relaxation approach.

\section{Area effect}

If area is a surrogate for population size then, on theoretical grounds (Hanski, 1994; Lande, 1993), an inverse relationship is predicted between extinction rate and area. Our finding confirms this expectation and is consistent with earlier empirical studies (Diamond, 1972; Halley and Iwasa, 2011; Hugueny, 2017). The estimated strength of the extinction-area relationship varies depending on the method used to estimate initial species richness. In the absence of co-variables and for models accounting for an age effect (A models with and without piscivores), the mean estimate is -0.67 , which is similar to the values estimated with the same modelling framework for terrestrial vertebrates, -0.53 (Hugueny, 2017), and river fishes, -0.56 (Hugueny et al., 2011). However, the range of our estimates is rather wide $(-1.25$ to -0.08), and when co-variables are added to the model, the estimated parameter value is even more variable, and sometimes null (the highest value that we considered realistic are returned). We suspect that the narrow range of lake sizes in this data set results in a rather 
weak area signal (see also Öhman et al., 2006) that can be swamped by the stochasticity inherent to species poor communities or erased when the effects of co-varying variables are accounted for. On this basis, it is not surprising that the area effect was weaker in the analyses conducted by excluding the piscivores as the initial species richness is particularly low in this case. Indeed, for the analyses that exclude the piscivores the average estimated value was low, -0.05 , suggesting that area had a weak effect at best. In light of our results, it is therefore difficult to assess whether or not the relationship between extinction rate and area is lacustrine-specific or if a general pattern exists for freshwater fish or all vertebrates.

pH effect

Natural and anthropogenic acidity is a chemical factor known to structure lacustrine fish communities in many regions (Bergquist BC, 1991; Haines, 1981; Rahel, 1984). In our study system acidity is due primarily to natural processes (Öhman et al., 2006). The negative effects of acidity on fish populations are both direct, through impaired gill function and ionoregulation for instance (Fromm, 1980), and indirect such as increasing aluminium toxicity (Wigington Jr. et al., 1996). The inclusion of $p H$ in our models largely increased AICc values compared to models without it. Overall, we observed that acid-stressed lakes experienced higher rates of extinctions than more neutral ones, as observed for anthropogenic acidification in other parts of Sweden (Bergquist BC, 1991). This result is coherent with a previous study showing that, in the same region, the occurrence of most fish species was negatively correlated to lake acidity (Öhman et al., 2006), pike and perch being the more tolerant (see also Bergquist BC, 1991). For instance, survey of many lakes showed small probability of finding roach at $\mathrm{pH}$ lower than six (Holmgren and Buffam, 2005). Studies of anthropogenic acidification suggest that extinction of populations is due to recruitment failure (Bergquist 1991) because the young stages (eggs, fry and alevins) are more vulnerable to acidity. 
We observed that the average extinction rate per species per year was negatively related to the

338 time elapsed since isolation of the lake, as already noted for terrestrial communities isolated in habitat fragments or islands (Hugueny, 2017). When extinction rates are estimated considering all the species and when area is the only explanatory variable, estimated values for parameter $m$ setting the strength of the age effect is estimated at 5.55. It is likely that those estimates are inflated because of the action of environmental variables that are correlated to altitude, and hence to age of the lakes. When depth and/or $\mathrm{pH}$ are added as co-variables, the estimates for the age effect are lower, about 4.4 on average, and comparable to the value of 3.9 estimated for terrestrial vertebrates (Hugueny, 2017).

A plausible explanation for an age effect is interspecific variability in extinction proneness (Ferraz et al., 2003). Indeed, species that are more sensitive to go extinct (e.g., due to small population size or long generation time) are more likely to disappear rapidly after the isolation events, while species more resistant to extinctions are more likely to persist. This mechanism is analogous to the term "extinction filter" which was used by (Balmford, 1996) to explain why communities may appear more resilient to particular threats if they have faced similar challenges in the past. Restricting the analyses to non-piscivorous species led to a considerably lower age effect (ca. 1) then when all the species are included, giving strong support to the extinction filter hypothesis. Predator species generally have lower population sizes than other species because of the higher energetic demand imposed by their large body size and top position in the food web and, as a result, are extinction-prone species. The fact that the two focal piscivorous species (pike and perch) are particularly vulnerable to winter kill arising from low oxygen levels under the ice, is also worth considering in this regard. In this line of reasoning, excluding pike and perch from analyses is likely to result in lake assemblages with lower interspecific variability in extinction proneness and to weaken the strength of the age effect on species loss rate. 
Another hypothesis for explaining that extinction rate per species is lower in older lakes is ecological release resulting from the absence of competitors or predators. If some pairs of coexisting species are involved in biotic interactions sufficiently strong to induce population declines or to reduce population densities, then extinction rate per species should be higher in species rich, young, assemblages than in old and species-poor ones. Some diversity dependent models (e. g. Halley et al., 2016) allow integrating the number of coexisting species (more specifically the number of species present at the time of isolation) as a factor controlling extinction rate per species. Unfortunately, they are of limited use in our case because there is not enough variability in the estimated species richness at the time of isolation to assess its contribution to species loss rate. In addition, because our initial species richness is estimated from lake features and not directly extracted from empirical data, it is not possible to separate the effect of the variable entered into the equation used to predict the initial species richness from the direct effect of species richness itself.

\section{Piscivores effect}

In contrast with competition, the effects of predators on the loss rates of prey species can be assessed in our study system. The best model including the presence of piscivores as a covariable is outperformed by the best model without a predation effect, however the difference in AICc values is small ( $\triangle \mathrm{AICc}=3.3$ ). The presence of northern pike and perch positively influenced extinction rates showing that predation by northern pike and perch can cause extinctions at community levels in isolated lakes. We also found that the best models with a predation effect were those with $\mathrm{pH}$ and depth as additional co-variables. Interestingly in those models we observed that extinction rates and depth are positively correlated while in models fitted with all species depth always contributed negatively to extinction rates. The contribution of pike and perch to species loss rate is concordant with results from a previous study of the same system of isolated lakes in which negative co-occurrence between predators 
and prey were observed and interpreted as the result of prey extinction in the presence of predators (Englund et al., 2009). There are other strong evidences in the literature that northern pike influence the abundance and size distributions of crucian carp (Brönmark et al., 2018). The presence of large piscivorous perch is also known to hinder the re-establishment of roach, unless coexistence of perch and roach is mediated by the presence of pike (Persson et al., 2006). Monitoring small lakes after the introduction of perch or pike revealed rapid extinction (within less than 50 years) of nine-spined and three-spined sticklebacks (Englund et al., 2009) and small cyprinidae (Nicholson ME, Rennie MD, 2015). The fact that piscivores enter the best models only in combination with depth clearly suggest that their impact on prey species is sufficiently strong to induce extinction in deep lakes but this outcome is less likely in shallow lakes confirming the complex relationships between piscivores, preys and depth already emphasized in a previous study of the very same system (Englund et al., 2009). Perch and northern pike are more likely to occur in deep lakes (Englund et al., 2009; MacDougall et al., 2018; Magnuson et al., 1998) which are buffered against winter kill (i.e., arising from low oxygen levels under the ice) which induce fish to suffocate (Petrosky and Magnuson, 1973). Therefore, when these two species are taken into account to estimate extinction rates, depth and species loss rate are negatively related as they are more likely to persist in deep lakes. In contrast, when those two piscivores are excluded of the estimation of extinction rates, there is a positive relationship between depth of lakes and extinction rates as in deep lakes piscivores are more likely to occur and are responsible for extinctions of prey species. When predators occur in shallow lakes they are probably present at low density and coexistence with the more vulnerable preys could be facilitated. Shallow lakes are also known to offer refugee from piscivores, such as abundant macrophytes (Sand Jensen \& Borum 1991, Snickars 2009). Finally, pike and perch are generalist predators that can potentially drive one or several prey species to extinction without undermining their own persistence. For instance, in our database 
there are lakes where pike is the only recorded fish species, which is plausible as pike may feed on insects, ducklings and small pike (Dessborn et al., 2010; Venturelli and Tonn, 2006), even rather large pike can have insects as a major part of the diet. However, it is likely that extinction is not the outcome of all prey-predator interactions taking place in the studied lakes. First, as discussed before, predator impact is dependent upon lake environmental features such as depth or $\mathrm{pH}$ that may influence trophic dynamics but also population sizes. Second adults of the largest prey species such as carp and roach may be difficult to handle for a perch and even a pike. Third both preys and predators feed on zooplankton in their youngest stages and a prey may therefore have a negative impact on predator population dynamics through competition (Byström et al., 1998). For these reasons it is likely that the contribution of predation to species loss rate in isolated lakes is limited in our system mostly to the two stickleback species as suggested by the fact that these two species are rapidly extirpated after piscivore introductions and possibly to carp which rarely coexist with predatory fishes.

\section{Limitations}

Some limitations inherent to our study suggest that some of our findings should be treated with caution. For instance, species richness at time of isolation was modelled, rather than observed, which likely introduces some errors in our calculations (though such data are rarely available, especially at such time scale). The sensitivity analyses of initial species richness had little effect on the estimation of species loss rate per lake on average (Appendix 6). This robustness suggests that, as a whole, our estimates are trustworthy and could be compared to those from other systems. The comparison of species loss rate among lakes with the aim to identify underlying biotic or abiotic factors is much more dependent on the way initial species richness was estimated. However, even in this case, robust results emerged such as a strong and consistent effect of age and $\mathrm{pH}$ and the synergetic action of piscivory and depth. Based on geomorphological arguments we assumed that no natural colonization events have taken place 
in those lakes but we cannot discard with certainty that some (but few) populations have been introduced by humans. Indeed, high quality historical data is a key limiting factor for studying extinction at the scale of centuries and millenia. Based on interviews of fishery rights owners, only lakes where the interviewees claimed that species introductions had not occurred were included. This does not preclude very old introductions or introductions made without informing the fishery rights owner. Such introductions would lead to underestimates of the extinction rate. Lack of data for population abundances also prevented us from exploring extinction rates at species level and more generally to rank species according to their extinction proneness. Moreover, because of the low prevalence of some species (Nine-spined stickleback, $90 \%$ of absences; three-spined stickleback: $97 \%$ of absences), it was not possible to conduct statistical analyses to investigate factors that may influence their extinction rate, and in particular the role of predators. We also investigate extinction rates considering each lake as an independent unit, but it is most likely that nearby lakes share environmental features not considered in our analyses. Finally, other drivers (not taking into account in our analyses due to data availability) might influence species loss rates in this system. For instance, the effects of anthropogenic activities (e.g., forestry and ditching for forestry production) on fish extinction rates in this area are largely unknown. Moreover, productivity in those lakes is mostly limited by light rather than nutrients. Light limitation is related to water color, which in turn is well correlated with the size of the catchment. Thus, had there been strong effects of productivity on extinction rates, we would expect catchment area to represent this effect.

\section{Implications}

Our study revealed that to some extent isolated lakes are not so different from terrestrial isolates (islands, habitat patches, ...) with regard to the dynamics of species loss. In both 
cases species loss rate decreases as time since isolation elapses and extinction rates are higher in small isolates. While based on different processes, age is also a strong component of the unified theory of island biogeography (Borregaard et al., 2016; Whittaker et al., 2008) stressing that this factor should not be overlooked in future works conducted on both true islands and island-like habitats. We also observed peculiarities specific to lacustrine habitat regarding extinction patterns. In particular, we observed that prey extinction rates seem to be regulated by the interplay between depth and predation, which is in line with a conceptual framework for lacustrine community dynamics elaborated by Tonn W. M. and Magnuson (1982). Those observations suggest that our study has a good level of representativeness in light of the available knowledge about vertebrate extinction patterns and lacustrine community dynamics.

\section{Conclusion}

Our results add to recent studies (Halley et al., 2016; Hugueny, 2017) that emphasize the implications of unpaid extinction debts in isolated habitats for conservation and environmental impact assessments. Many studies modeling future effects of climate change, land use changes, or biological invasions on biodiversity have neglected extinction debts and the implied community and population processes. Knowing at which rate those anticipated extinctions will occur is paramount when prioritizing conservation actions. This is particularly true for freshwaters which cover less than $1 \%$ of the earth's surface while supplying $12 \%$ of the fish consumed by humans and are increasingly fragmented by human activities. Recently it has been shown that delayed extinctions in terrestrial vertebrates could be analyzed within a common framework. Unfortunately, such a synthesis is not at hand for freshwater fishes because too few relevant studies have been conducted. A more promising avenue is to test whether generalities observed for terrestrial vertebrate hold true for freshwater ones. 


\section{Acknowledgements}

489

490

491

492

493

494

495

496

497

498

499

500

501

502

503

504

505

506

507

508

509

510

511

512

513

514

515

516

517

This work has been supported by the BiodivERsA project ODYSSEUS funded from the

European Union's Horizon 2020 research and innovation program. BH is supported by the

French Laboratory of Excellence project "TULIP" (ANR-10-LABX-41 ; ANR-11-IDEX-

0002-02).

\section{Data Accessibility}

Data of isolated lakes used in this manuscript are available in a dryad deposit (https://doi:10.5061/dryad.5sv75bd/1).

\section{Author's contributions}

GE provided the data, $\mathrm{CB}$ and $\mathrm{BH}$ designed the study and conducted the analyses. All the authors interpret the results and $\mathrm{CB}$ wrote the first draft of the manuscript.

\section{References}

Almeida, R. J., Biro, E. G., Woods, L. M., and Smith, K. G. (2017). Species abundance plays a dominant role in local and regional extinctions in freshwater communities and allows the identification of selective extinctions. bioRxiv. doi:https://doi.org/10.1101/219469.

Appelberg, M., Berger, H.-M., Hesthagen, T., Kleiven, E., Kurkilahti, M., Raitaniemi, J., et al. (1995). Development and intercalibration of methods in nordic freshwater fish monitoring. Water. Air. Soil Pollut. 85, 401-406. doi:10.1007/BF00476862.

Balmford, A. (1996). Extinction filters and current resilience: the significance of past selection pressures for conservation biology. Trends Ecol. Evol. 11, 193-6.

Bellard, C. Englund, G. \& B. Hugueny (2019). Data from: Biotic and abiotic drivers of species loss rate in isolated lakes. Dryad Digital Repository. doi:10.5061/dryad.5sv75bd

Bergquist BC (1991). Extinction and natural colonization of fish in acidified and limed lakes. Nord. J. Freshw. Res., 50-62.

Borregaard, M., Isabel, A., A, B. P., Juliano, C., José, F.-P., Richard, F., et al. (2016). Oceanic island biogeography through the lens of the general dynamic model: assessment and prospect. Biol. Rev. 92, 830-853. doi:10.1111/brv.12256.

Brönmark, C., Paszkowski, C., Tonn, W., and Hargeby, A. (2018). Predation as a determinant of size structure in populations of crucian carp (Carassius carassius) and tench (Tinea tinea). Ecol. Freshw. Fish 4, 85-92. doi:10.1111/j.1600-0633.1995.tb00121.x. 
Burnham, K. P. \& Anderson, D. R. (2002). Model selection and multimodel inference: $a$ practical information-theoretic approach. Springer.

Byström, P., Persson, L., and Wahlström, E. (1998). Competing predators and prey: juvenile bottlenecks in whole-lake experiments. Ecology 79, 2153-2167.

Ceballos, G., Ehrlich, P. R., Barnosky, A. D., Garcia, A., Pringle, R. M., and Palmer, T. M. (2015). Accelerated modern human-induced species losses: Entering the sixth mass extinction. Sci. Adv. 1, e1400253-e1400253. doi:10.1126/sciadv.1400253.

Ceballos, G., Ehrlich, P. R., and Dirzo, R. (2017). Biological annihilation via the ongoing sixth mass extinction signaled by vertebrate population losses and declines. Proc. Natl. Acad. Sci. 114, E6089 LP-E6096. Available at: http://www.pnas.org/content/114/30/E6089.abstract.

Collen, B., Whitton, F., Dyer, E. E., Baillie, J. E. M., Cumberlidge, N., Darwall, W. R. T., et al. (2014). Global patterns of freshwater species diversity, threat and endemism. Glob. Ecol. Biogeogr. 23, 40-51. doi:10.1111/geb.12096.

Cousins, S. A. O., and Vanhoenacker, D. (2011). Detection of extinction debt depends on scale and specialisation. Biol. Conserv. 144, 782-787. doi:https://doi.org/10.1016/j.biocon.2010.11.009.

Cronk, Q. (2016). Plant extinctions take time. Science (80-. ). 353, 446 LP-447. Available at: http://science.sciencemag.org/content/353/6298/446.abstract.

De Vos, J. M., Joppa, L. N., Gittleman, J. L., Stephens, P. R., and Pimm, S. L. (2014). Estimating the normal background rate of species extinction. Conserv. Biol. 29, 452462. doi:10.1111/cobi.12380.

Dessborn, L., Elmberg, J., and Englund, G. (2010). Pike predation affects breeding success and habitat selection of ducks. Freshw. Biol. 56, 579-589. doi:10.1111/j.13652427.2010.02525.x.

Diamond, J. (1972). Biogeographic kinetics: estimation of relaxation times for avifaunas of Southwest Pacific islands. Proc. Natl. Acad. Sci. 69, 3199-3203.

Dias, M. S., Tedesco, P. A., Hugueny, B., Jézéquel, C., Beauchard, O., Brosse, S., et al. (2017). Anthropogenic stressors and riverine fish extinctions. Ecol. Indic. 79, 37-46. doi:10.1016/J.ECOLIND.2017.03.053.

Englund, G., Johansson, F., Olofsson, P., Salonsaari, J., and Öhman, J. (2009). Predation leads to assembly rules in fragmented fish communities. Ecol. Lett. 12, 663-671. doi:10.1111/j.1461-0248.2009.01322.x.

Ferraz, G., Russell, G. J., Stouffer, P. C., Bierregaard, R. O., Pimm, S. L., and Lovejoy, T. E. (2003). Rates of species loss from Amazonian forest fragments. Proc. Natl. Acad. Sci. U. S. A. 100, 14069-73. doi:10.1073/pnas.2336195100.

Fromm, P. O. (1980). A review of some physiological and toxicological responses of freshwater fish to acid stress. Environ. Biol. Fishes 5, 79-93. doi:10.1007/BF00000954.

Haines, T. A. (1981). Acidic Precipitation and Its Consequences for Aquatic Ecosystems: A Review. Trans. Am. Fish. Soc. 110, 669-707. doi:10.1577/15488659(1981)110<669:APAICF>2.0.CO;2.

Halley, J. M., and Iwasa, Y. (2011). Neutral theory as a predictor of avifaunal extinctions 
after habitat loss. Proc. Natl. Acad. Sci. U. S. A. 108, 2316-2321. doi:10.1073/pnas.1011217108.

Halley, J. M., Monokrousos, N., Mazaris, A. D., Newmark, W. D., and Vokou, D. (2016). Dynamics of extinction debt across five taxonomic groups. Nat. Commun. 7, 12283. doi:10.1038/ncomms12283.

Hanski, I. (1994). A practical model of metapopulation dynamics. J. Anim. Ecol. 63, 151-162.

Harding, J. S., Benfield, E. F., Bolstad, P. V., Helfman, G. S., and Jones, E. B. D. (1998). Stream biodiversity: The ghost of land use past. Proc. Natl. Acad. Sci. 95.

He, F., and Hubbell, S. P. (2011). Species-area relationships always overestimate extinction rates from habitat loss. Nature 473, 368-371. doi:10.1038/nature09985.

Helm, A., Hanski, I., and Pärtel, M. (2005). Slow response of plant species richness to habitat loss and fragmentation. Ecol. Lett. 9, 72-77. doi:10.1111/j.1461-0248.2005.00841.x.

Holmgren, K. (2014). Challenges in assessing biological recovery from acidification in Swedish lakes. Ambio 43 Suppl 1, 19-29. doi:10.1007/s13280-014-0559-y.

Holmgren, K., and Buffam, I. (2005). Critical values of different acidity indices - as shown by fish communities in Swedish lakes. SIL Proceedings, 1922-2010 29, 654-660. doi:10.1080/03680770.2005.11902760.

Hugueny, B. (2017). Age-area scaling of extinction debt within isolated terrestrial vertebrate assemblages. Ecol. Lett. 20, 591-598. doi:10.1111/ele.12756.

Hugueny, B., Movellan, A., and Belliard, J. (2011). Habitat fragmentation and extinction rates within freshwater fish communities: a faunal relaxation approach. Glob. Ecol. Biogeogr. 20, 449-463. doi:10.1111/j.1466-8238.2010.00614.x.

Hylander, K., and Ehrlén, J. (2013). The mechanisms causing extinction debts. Trends Ecol. Evol. 28, 341-346. doi:https://doi.org/10.1016/j.tree.2013.01.010.

Krauss, J., Bommarco, R., Guardiola, M., Heikkinen, R. K., Helm, A., Kuussaari, M., et al. (2010). Habitat fragmentation causes immediate and time-delayed biodiversity loss at different trophic levels. Ecol. Lett. 13, 597-605. doi:10.1111/j.1461-0248.2010.01457.x.

Kuussaari, M., Bommarco, R., Heikkinen, R. K., Helm, A., Krauss, J., Lindborg, R., et al. (2009). Extinction debt: a challenge for biodiversity conservation. Trends Ecol. Evol. 24, 564-571. doi:https://doi.org/10.1016/j.tree.2009.04.011.

Lande R (1993). Risks of population extinction from demographic and environmental stochasticity and random catastrophes. Am. Nat. 142, 911-927.

Leclerc, C., Courchamp, F., and Bellard, C. (2018). Insular threat associations within taxa worldwide. Sci. Rep. 8. doi:10.1038/s41598-018-24733-0.

Lindborg, R., and Eriksson, O. (2004). Historical landscape connectivity affects present plant species diversity. Ecology 85, 1840-1845. doi:10.1890/04-0367.

MacDougall, A. S., Harvey, E., McCune, J. L., Nilsson, K. A., Bennett, J., Firn, J., et al. (2018). Context-dependent interactions and the regulation of species richness in freshwater fish. Nat. Commun. 9, 973. doi:10.1038/s41467-018-03419-1.

Magnuson, J., William, T., Asit, B., Jorma, T., Oliva, S., and Rask Martti (1998). Isolation vs. 
extinction in the assembly of fishes in small northern lakes. Ecology 79, 2941-2956. doi:10.1890/0012-9658(1998)079[2941:IVEITA]2.0.CO;2.

Nicholson ME, Rennie MD, M. K. (2015). Apparent extirpation of prey fish communities following the introduction of northern pike (Esox Lucius). Can. F. Nat. 129, 165-173.

Öhman, J., Buffam, I., Englund, G., BLOM, A., Lindgren, E., and Laudon, H. (2006). Associations between water chemistry and fish community composition: a comparison between isolated and connected lakes in northern Sweden. Freshw. Biol. 51, 510-522. doi:10.1111/j.1365-2427.2006.01514.x.

Pereira, H. M., Leadley, P. W., Proença, V., Alkemade, R., Scharlemann, J. P. W., FernandezManjarrés, J. F., et al. (2010). Scenarios for global biodiversity in the 21 st century. Science 330, 1496-501. doi:10.1126/science.1196624.

Persson, L., De roos, A. M., and Bystrom, P. Ä. R. (2006). State-dependent invasion windows for prey in size-structured predator-prey systems: whole lake experiments. J. Anim. Ecol. 76, 94-104. doi:10.1111/j.1365-2656.2006.01190.x.

Petrosky, B. R., and Magnuson, J. J. (1973). Behavioral Responses of Northern Pike, Yellow Perch and Bluegill to Oxygen Concentrations under Simulated Winterkill Conditions. Copeia 1973, 124-133. Available at: http://www.jstor.org/stable/1442367.

Piessens, K., and Hermy, M. (2006). Does the heathland flora in north-western Belgium show an extinction debt? Biol. Conserv. 132, 382-394. doi:10.1016/J.BIOCON.2006.04.032.

Piha, H., Luoto, M., and Merilä, J. (2007). Amphibian occurrence is influenced by current and historic landscape characteristics. Ecol. Appl. 17, 2298-309. Available at: http://www.ncbi.nlm.nih.gov/pubmed/18213970 [Accessed March 6, 2018].

R Core Team (2017). R: A language and environment for statistical computing. R Foundation for Statistical.

Rahel, F. J. (1984). Factors Structuring Fish Assemblages Along a Bog Lake Successional Gradient. Ecology 65, 1276-1289. doi:10.2307/1938333.

Sala, O. E., Iii, F. S. C., Armesto, J. J., Berlow, E., Bloomfield, J., Dirzo, R., et al. (2000). Global Biodiversity Scenarios for the Year 2100. Science (80-. ). 287, 1770-1774.

Seekell, D. A., Lapierre, J.-F., Ask, J., Bergström, A.-K., Deininger, A., Rodríguez, P., et al. (2015). The influence of dissolved organic carbon on primary production in northern lakes. Limnol. Oceanogr. 60, 1276-1285. doi:10.1002/lno.10096.

Shaw, D. W., Escalante, P., Rappole, J. H., Ramos, M. A., Oehlenschlager, R. J., Warner, D. W., et al. (2013). Decadal changes and delayed avian species losses due to deforestation in the northern Neotropics. PeerJ 1, e179. doi:10.7717/peerj.179.

Tonn W. M., and Magnuson, J. J. (1982). Patterns in the Species Composition and Richness of Fish Assemblages in Northern Wisconsin Lakes. Ecology 63, 1149-1166.

Uezu, A., and Metzger, J. P. (2016). Time-Lag in Responses of Birds to Atlantic Forest Fragmentation: Restoration Opportunity and Urgency. PLoS One 11, e0147909. doi:10.1371/journal.pone.0147909.

Venturelli, P. A., and Tonn, W. M. (2006). Diet and Growth of Northern Pike in the Absence of Prey Fishes: Initial Consequences for Persisting in Disturbance-Prone Lakes. Trans. Am. Fish. Soc. 135, 1512-1522. doi:10.1577/T05-228.1. 
651

652

653

654

655

656

657

658

659

\begin{tabular}{lll}
\hline Model & Contributing variables & $\begin{array}{l}\text { Parameters } \\
\text { considered }\end{array}$ \\
\hline A & Area & $b, m$, \\
ApH & Area pH & $b, m, x$ \\
Apisc & Area Piscivory & $b, m, v b$ \\
Adepth & Area Depth & $b, m, y$ \\
Full & Area Piscivory pH Depth & $b, m, x, v b, y$ \\
\hline
\end{tabular}

Wigington Jr., P. J., DeWalle, D. R., Murdoch, P. S., Kretser, W. A., Simonin, H. A., Van Sickle, J., et al. (1996). Episodic Acidification of Small Streams in the Northeastern

Tables

Table 1: Description of the models predicting average annual species loss rate

660 United States: Ionic Controls of Episodes. Ecol. Appl. 6, 389-407. doi:10.2307/2269378.

661

662

663

664

665

666 
Table 2: Comparison of models using eq 1 to predict average annual species loss rates on two datasets (including or excluding piscivores when calculating initial richness). For each dataset, the best model is highlighted in bold. AICc is the Akaike information criterion with a correction for small sample sizes, $k$ is the number of free parameters and the sign of the parameters are shown (see eq. 1 for parameter descriptions). Parameters values are given in 680 Appendix S2.

\begin{tabular}{|c|c|c|c|c|c|c|c|c|}
\hline \multicolumn{8}{|c|}{ Including piscivores } & \\
\hline Models & Intercept $(c)$ & Area (b) & Age (m) & $p H(x)$ & $\operatorname{Pisc}(v b)$ & $\operatorname{Depth}(y)$ & $\mathrm{AICc}$ & $k$ \\
\hline ApH & + & - & + & - & & & 178.1 & 4 \\
\hline Full & + & - & + & - & & - & 179.1 & 5 \\
\hline Adepth & + & - & + & & & - & 187.9 & 4 \\
\hline $\mathrm{A}$ & + & - & + & & & & 193.2 & 3 \\
\hline \multicolumn{9}{|c|}{ Excluding piscivores } \\
\hline ApH & + & $\mathbf{0}$ & + & - & & & 147.5 & 4 \\
\hline Full & + & 0 & + & - & + & + & 150.8 & 6 \\
\hline A & + & - & + & & & & 153.2 & 3 \\
\hline Apisc & + & - & + & & + & & 155.3 & 4 \\
\hline Adepth & + & - & + & & & - & 155.4 & 4 \\
\hline
\end{tabular}

\section{Figure captions}



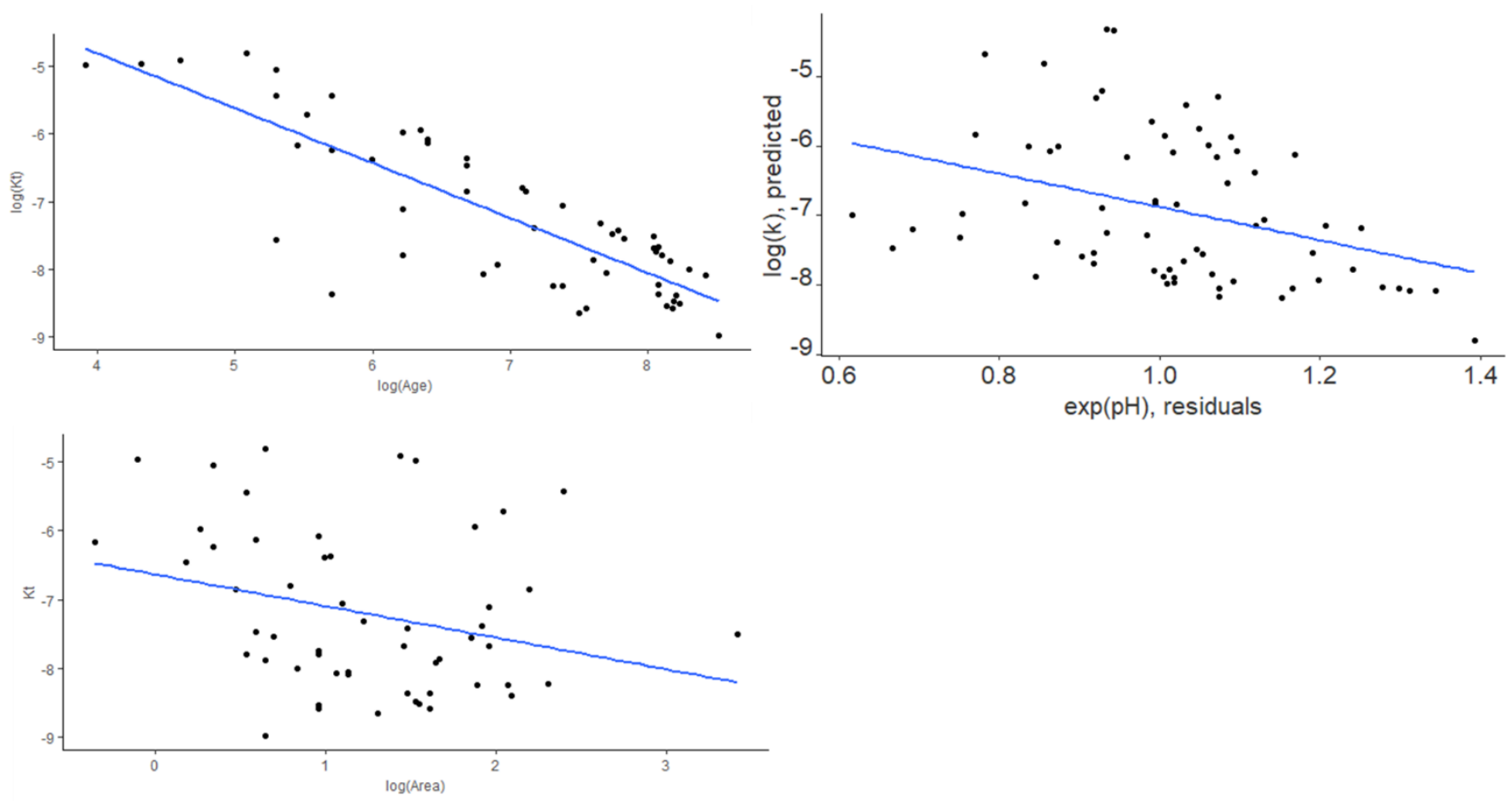

685 Figure 1: Observed average annual species loss rate $(k)$ as a function of the area and age of isolated lakes and predicted annual species loss rates $(\mathrm{k})$ as a function of $\mathrm{pH}$ residuals. Area and age were natural log transformed. The loss rates were calculated with eq 3 . 
A

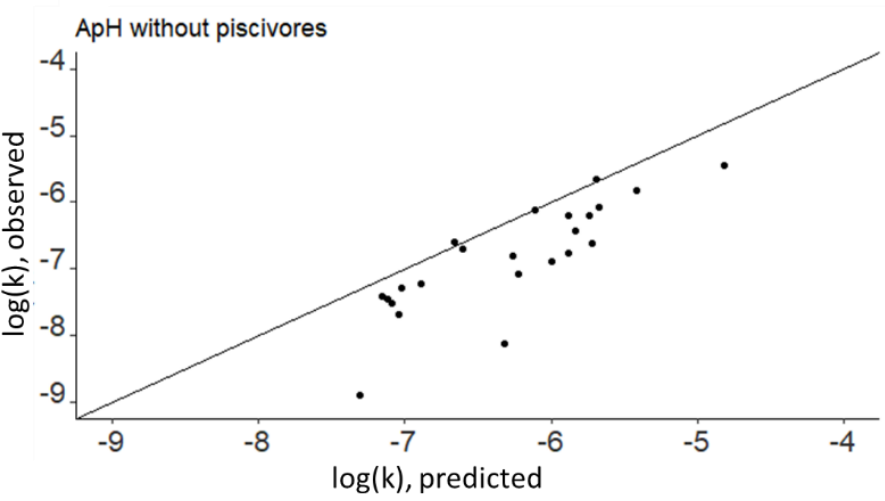

B

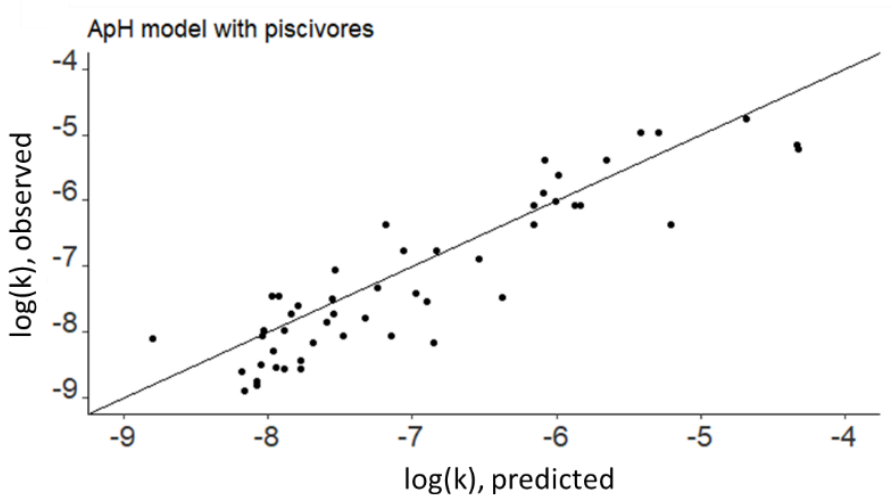

690

691 Figure 2: Observed average annual species loss rates $(k)$ plotted against the values predicted

692 by the ApH model. The line of perfect agreement between model prediction and observation 693 is shown.

694 